\title{
La estética del cuidado; la creación como actitud y compromiso
}

\author{
Laia MANONELles Moner \\ Universidad de Barcelona \\ Departamento de Historia del Arte \\ laiamanonelles@ub.edu
}

Recibido: 26-12-2015

Aceptado: 30-09-2016

\section{RESUMEN}

Este artículo tiene como objetivo analizar la ética y la estética del cuidado relacionándola con prácticas artísticas colaborativas en las que se fusiona la experiencia vital con la artística. Esta estrecha vinculación entre la esfera íntima y la social nos remite a la consigna "Lo personal es político" (1969), de la feminista Carol Hanisch, que sirve de punto de partida a numerosas artistas, enfocando aquello que tradicionalmente se ha resguardado en el campo de la privacidad. Estas premisas se articularán a partir de varias iniciativas - de artistas como Eulàlia Valldosera, Marga Ximénez y Nora Ancarola- que profundizan en las relaciones de las estructuras familiares y sociales. En las conclusiones se señala, a partir del análisis de casos concretos, cómo la creación puede devenir un instrumento para potenciar un pensamiento crítico y para politizar el malestar social.

Palabras clave: Arte de acción; Arte y política; Arte relacional; Ética del cuidado; Eulàlia Valldosera; Marga Ximénez; Nora Ancarola.

\section{The aesthetics of care; creation as attitude and commitment}

\begin{abstract}
This article sets out to analyze the ethics and aesthetics of care in relation to collaborative art practices in which life experience is fused with the artistic creation. This close link between the intimate and the social sphere leads us to the slogan "The personal is political" (1969), of the feminist Carol Hanisch, which serves as the starting point for numerous artists, focusing on what has been traditionally protected in the field of privacy. These premises will be articulated from various initiatives -from artists like Eulàlia Valldosera, Marga Ximenez and Nora Ancarola- that explore relationships in social and family structures. We conclude, based on the analysis of specific cases, in pointing out how creation could become a tool to increase critical thinking and a way to politicize social malaise.
\end{abstract}

Keywords: Performance art; Art and politics; Relational art; Aesthetics and ethics of care; Eulàlia Valldosera; Marga Ximénez; Nora Ancarola.

Sumario: Introducción; lo personal es político. Constelaciones y lazos familiares en el trabajo de Eulàlia Valldosera. La ética del cuidado: Antikeres y la Trilogía de la privacidad de Nora Ancarola y Marga Ximénez. Conclusiones. 


\section{Introducción; lo personal es político}

La ética y la estética del cuidado, la gestión de la vulnerabilidad y la determinación de analizar y ahondar en los lazos relacionales, son temas en los que profundizan varios artistas que fusionan la experiencia vital con los procesos creativos. Esta estrecha relación entre las vivencias individuales y las colectivas nos remite directamente a la consigna "Lo personal es político" que plantearon Carol Hanisch, en su artículo The Personal Is Political en febrero del $1969^{1}$, y Kate Millet en su libro Sexual's politics en1969. Precisamente, una de las claves del movimiento feminista, en la década de los sesenta y los setenta en los Estados Unidos, fue la creación de grupos de autoconciencia o grupos de concienciación política (consciousness-raising) en los que cada mujer exponía experiencias personales -en relación a varios temas como la sexualidad, el trabajo, las relaciones familiares y las estructuras del poder- $y$, después de la puesta en común, se analizaban de manera grupal los pensamientos planteados. Carol Hanisch, quien colaboraba estrechamente con las plataformas feministas Women's Liberation Movement y New York Radical Women, reflexiona sobre la potencialidad terapéutica de estas reuniones y utiliza el término "terapia política" (political therapy) para recalcar que no se trataba de un ejercicio individual sino que se trataba de un ejercicio político al analizar el malestar sistémico, social. Desde estos grupos de autoconciencia o de concienciación política se pensaban acciones comunitarias para afrontar problemas colectivos:

"So the reason I participate in these meetings is not to solve any personal problem. One of the first things we discover in these groups is that personal problems are political problems. There are no personal solutions at this time. There is only collective action for a collective solution. [...] This is not to deny that these sessions have at least two aspects that are therapeutic. I prefer to call even this aspect "political therapy" as opposed to personal therapy"2.

El planteamiento "lo personal es político" fue ampliamente difundido por los grupos activistas feministas, señalando cómo los sistemas patriarcales marcan una clara distinción entre un espacio productivo y público relacionado principalmente con el género masculino y un espacio doméstico, privado y reproductivo vinculado tradicionalmente con el género femenino. Estas ideas fueron desarrolladas por numerosas artistas de la época y continúan vigentes y trabajándose en la actualidad, enfocando aquello que se omite y se resguarda en el campo de la privacidad.

La contraposición entre la "terapia política" y la terapia personal, que ya exponía Carol Hanish en 1969, es esencial pues a pesar de la irrupción de las corrientes antipsiquiátricas de los años setenta -que plantearon la politización del malestar- nos encontramos que trascurridas cuatro décadas todavía existe un alto nivel de psiquiatrización y psicologización en las sociedades occidentales que se concreta en una

1 Este artículo fue publicado en Notes from the Second Year: Women's Liberation, en 1970. HANISH, Carol, "The Personal Is Political", 1969. [En línea] www. carolhanisch.org/CHwritings/PIP.html [Consulta: 5 de abril el 2014].

2 HANISH, Carol, op. cit. 
amplia oferta asistencial "individual"3. Delante la psiquiatrización del malestar y la demanda psicológica "conductista" ¿qué papel asumen la psicología crítica o social, las prácticas artísticas y las personas que lidian con el sufrimiento? En los procesos de psiquiatrización y psicologización se trata al enfermo como un espectador pasivo, las terapias "privatizan" los padecimientos y -mediante el tratamiento- el desaliento pierde su significado social. En tal contexto, el arte deviene una de las vías para exponer, reivindicar y repensar la politización del malestar. La creación puede transformarse en un instrumento para compartir las realidades que se invisibilizan, aquello que la sociedad "pauta" que debe permanecer en la esfera íntima. A continuación se introducirán varias iniciativas - de artistas como Eulàlia Valldosera, Marga Ximénez y Nora Ancarola- que parten de esta voluntad comprometida. Dichas creadoras ahondan en su biografía, en su genealogía, o bien se convierten en mediadoras que acompañan a otras personas en la gestión de su sufrimiento. Dentro de tales premisas se construyen otros relatos alternativos al discurso hegemónico que modela unos determinados patrones sociales ¿Cómo se articulan estas narraciones? Mostrando ciertas realidades que se obvian como la gestión de los conflictos en la estructura social y familiar y el acompañamiento y cuidado a personas enfermas o dependientes. En los ejemplos que seguidamente se brindarán el proceso es fundamental. Es decir; el tiempo que se precisa para rumiar, digerir y recolocar lo vivido. Del mismo modo que también será especialmente importante la naturaleza colaborativa de tales propuestas artísticas, puesto que el objetivo final es generar nuevos espacios para reflexionar y dialogar.

\section{Constelaciones y lazos familiares en el trabajo de Eulàlia Valldosera}

Eulàlia Valldosera (Vilafranca del Penedés, 1963) articula su trabajo a partir de diversas disciplinas, como la fotografía, el arte de acción, la instalación y el vídeo, siendo la auto-representación esencial en sus propuestas artísticas. En varios de sus proyectos trata la relación entre lo privado y lo público, cuestionando abiertamente los estereotipos y los roles predefinidos que se perpetran en el marco de una sociedad patriarcal. En esta dirección hay que contextualizar sus propuestas Constelaciones (2003), en BilbaoArte, y Lazos Familiares (2012-13) que se exhibió en la Galería Maior de Mallorca (2012-13), en la galería Carroll \& Fletcher de Londres (2012) y en la exposición colectiva Modern Families (2013) en la Glucksman Gallery en Cork.

La intervención artística Constelaciones (2003), se compone de dos audiovisuales; Valentina (vídeo de doble canal, 23 minutos) (Fig. 1) y Gema (vídeo monocanal proyectado en una pared, 13 minutos), elaborados a partir de la documentación extraída en sesiones terapéuticas. Tal y como explicó la artista en la inauguración: "El material a partir del cual se ha elaborado la muestra ha sido registrado durante las sesiones terapéuticas que periódicamente se realizan en un centro [de terapia familiar] de Barcelona". En relación a esta decisión de trabajar directamente con los procesos tera-

3 MATA RUIZ, Iván; ORTIZ LOBO, Alberto, "La colonización psiquiátrica de la vida". Archipiélago, cuadernos críticos de la cultura, vol. 76, 2007, pp. 45-46. 

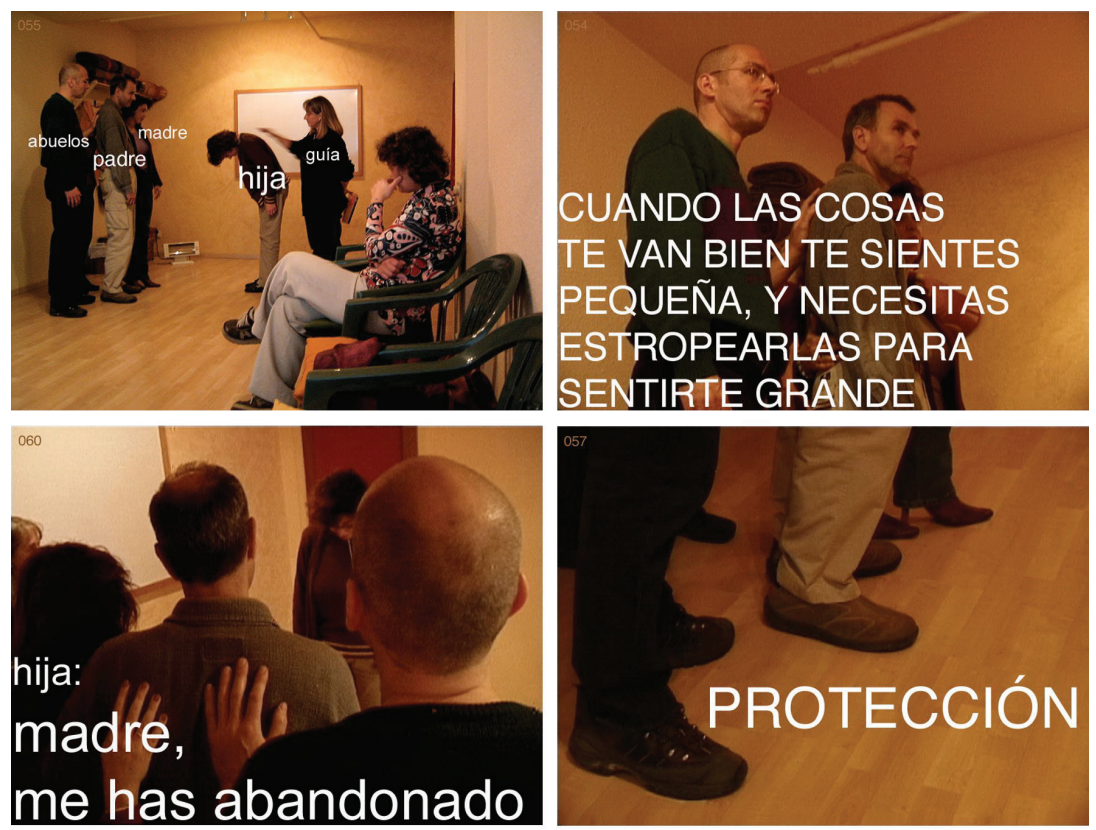

Fig. 1. Eulàlia Valldosera, Constelaciones Valentina (Secuencia vídeo de doble canal, 23 minutos, 2003). Imagen cortesía de la artista.

péuticos Eulàlia Valldosera comenta que "Este cambio, este buscar nuevos lenguajes, poner en duda lo que he venido haciendo tiene que ver con un momento personal. Mi maternidad me ha llevado a plantearme otras cosas". De este modo, mediante las constelaciones familiares, la autora puede "estudiar la narración y el papel que cada individuo y el lugar que ocupa juega en ella"4.

La artista parte del estudio de los árboles genealógicos para comprender, tratar y desanudar los conflictos que se generan en los linajes. Aquí es preciso introducir brevemente las constelaciones familiares, un proceso terapéutico que ha sido teorizado principalmente por Bert Hellinger (1925), de formación psicoanalítica. Esta psicoterapia tiene como objetivo principal identificar la transmisión de conflictos y las pautas de comportamiento patológico para así poder sanar las relaciones familiares. El método que se utiliza consiste en que cada persona, con la ayuda del terapeuta y de los integrantes del grupo terapéutico, configura su constelación familiar. Los miembros del grupo representan a los integrantes de la familia, escenifican el árbol genealógico para ayudar al consultante a poder visualizar las estructuras e interacciones de su linaje, definiendo así los problemas y, finalmente, -con toda la información- buscar soluciones posibles.

4 NIETO, Marta, "La artista Eulalia Valldosera explora la comunicación en una muestra en BilbaoArte", El Pais, 28 de junio de 2003. [En línea] www.elpais.com/diario/2003/06/28/paisvasco/1056829219_850215. html [Consulta: 5 junio de 2013]. 
Con todo, hay que destacar que Valldosera no se limita a un trabajo personal sino que se adentra en prácticas colaborativas, puesto que propone a otros artistas que participen y desarrollen sus propias constelaciones en talleres en los que se funde la terapia con la creación. Un ejemplo es el taller "Constelaciones, espacios y relaciones" (2006) con la finalidad de trabajar el proceso creativo, llevado a cabo conjuntamente con la terapeuta de constelaciones sistémicas Ana Trallero en La Magdalena el Taller de Artes Visuales 5 .

Otro trabajo que comparte el mismo objetivo de profundizar en la genealogía es el proyecto Lazos familiares (2012-2013) (Fig. 2), en el que la artista funde diversas fotografías en las que podemos ver a los distintos integrantes que componen una familia y a sus sombras y proyecciones. La autora amalgama los lazos conscientes e inconscientes, visibles e invisibles. Las constelaciones hacen emerger lo oculto, muestran cómo se imbrican las relaciones y revelan el espacio que cada sujeto ocupa en su familia.

Valldosera, en una conferencia que realizó en la Glucksman Gallery ${ }^{6}$ en motivo de su participación en la exposición colectiva Modern Families (2013) (Fig. 3), explicó

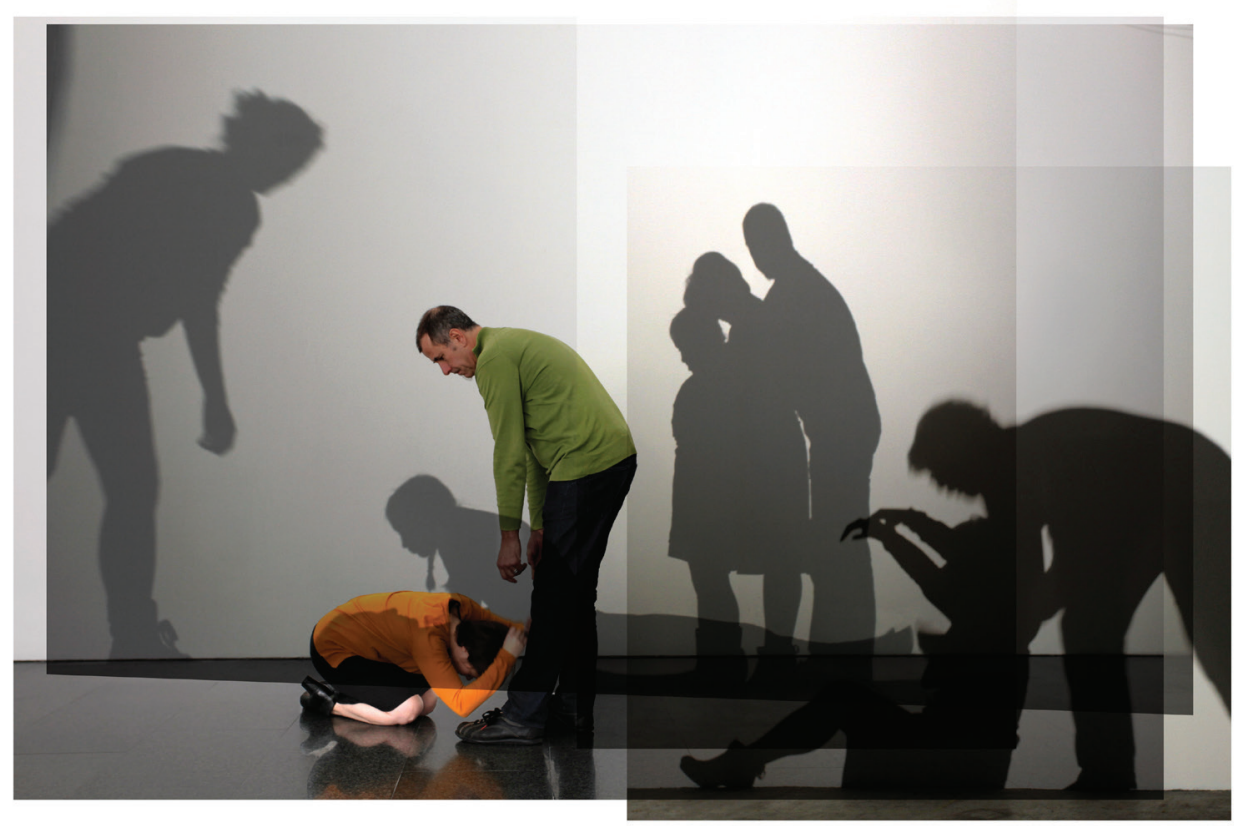

Fig. 2. Eulàlia Valldosera, Lazos familiares (2012). Imagen cortesía de la artista.

5 VALLDOSERA, Eulàlia, "Valldosera invita a los artistas a conocerse a través de sus 'constelaciones' particulares". [En línea] www.eldiariomontanes.es/prensa/20060809/cantabria/valldosera-invita-artistasconocerse_20060809.html [Consulta: 5 junio de 2013].

6 La conferencia tuvo lugar el 5 de setiembre de 2013 en el contexto de la jornada interdisciplinar The Body in Catalan Visual Culture, en la Universidad de Cork. 
que las fotografías retienen experiencias, vivencias, y se convierten en un testimonio. Superpone a las fotografías de los familiares sus propias sombras, tejiendo y destejiendo así los lazos que existen entre ellos. Las imágenes son protagonizadas por ella misma, su exmarido, su hijo, la mujer de su exmarido, el hijo de su exmarido. Plantea los distintos modelos familiares que se construyen en la actualidad a la vez que evidencia la tensión existente entre la estructura familiar "moderna" y la "tradicional". Otra artista que parte de los autorretratos fotográficos para revisar sus relaciones familiares es Jo Spence (1934, Londres- 1992) en la serie Beyond the family album (1978-79), en la que reescenifica situaciones de conflicto, puesto que se centra en lo que se esconde detrás de cada árbol genealógico. La artista aborda los roles determinados por la sociedad, se reconcilia con su madre y con los sentimientos reprimidos. Jo Spence comenzó a trabajar la "fototerapia", en 1984, con Rosy Martin, David Roberts y Tim Serrad, utilizando las técnicas de escenificación teatral del teatro épico de Bertold Brech y del teatro del oprimido de Augusto Boal. Al reconstruir los nudos existenciales deja de ser un sujeto pasivo y deviene un sujeto activo en la gestión de su malestar.

La fotografía es un medio para exponer temas sobre los que nadie quiere hablar, se pronuncia lo que era impronunciable y se afrontan situaciones complejas desde

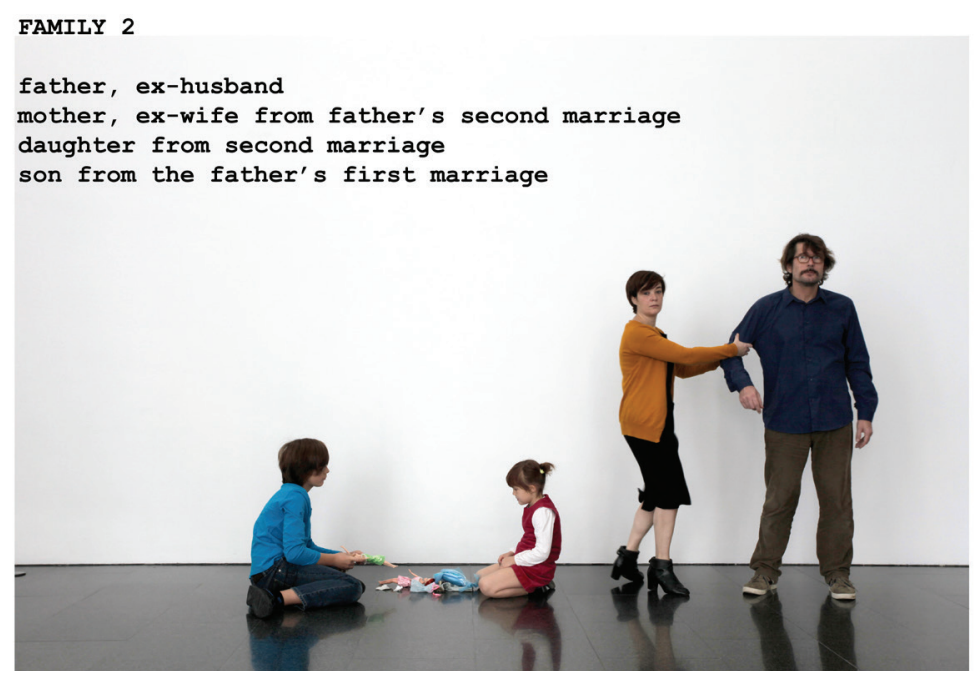

Fig. 3. Eulàlia Valldosera, Familly ties (2013). Imagen cortesía de la artista.

otra perspectiva. Jo Spence y Eulàlia Valldosera son tanto las fotógrafas como las protagonistas de las escenificaciones familiares que recrean, examinando desde distintos prismas las relaciones preestablecidas. Ambas se ubican delante y detrás de la 
cámara, exponiéndose y distanciándose de su propio cuerpo y entorno. En estas obras puede verse la decisión de cuestionar las pautas de comportamiento que dicta el sistema dominante para buscar la propia identidad escuchándose a sí mismas. Se trata de comprender la cartografía de relaciones sociales para poder, finalmente, elegir conscientemente donde recolocarse. Esta reubicación o reorientación es fundamental y es preciso recordar que el impacto va más allá del núcleo familiar porque también se pretenden redefinir las relaciones en la sociedad actual. Tal y como ya se ha introducido lo personal es político. Valldosera explica en una entrevista con Daniel Gasol:

"Parto de "la premisa de que "lo personal es político", que se expande ahora al terreno de lo social, entendido éste como un tejido donde las relaciones laborales y los intercambios personales urden tramas que afectan nuestra identidad y nuestro status social, tensando el significado de lo que supone la "normalidad" en tanto que eje mediador, por no decir limitador, de toda comunidad cultural"7.

En estrecha relación con lo previamente planteado es preciso mencionar al $\mathrm{Co}$ lectivo socialista de pacientes, quienes relacionaron la enfermedad psíquica con el modus operandi de la sociedad capitalista que aliena a los individuos y subrayaron la necesidad de gestionar colectivamente el malestar. Jean-Paul Sartre, en el prefacio al libro Hacer de la enfermedad un arma (1972) de dicho colectivo, enfatiza su dimensión política:

"Ce qui me paraît saisissant dans le SPK c'est que les patients sans médecin individuel - c'est-à-dire sans pôle individué des significations - établissent des relations humaines et s'aident les uns les autres à une prise de conscience de leur situation en se regardant dans les yeux, c'est-à-dire en tant que sujets signifiants-signifiés alors que dans la forme moderniste de la psychiatrie, la psychanalyse, le malade ne regarde personne et que le médecin est placé derrière lui pour enregistrer ses propos et pour les grouper comme il l'entend, cette détermination spatiale du rapport patient-médecin mettant le premier dans la situation d'un pur objet et faisant du second le signifiant absolu, déchiffrant le discours de la maladie par une herméneutique dont il prétend avoir seul le secret"8.

Hay que apuntar que en la actualidad el malestar no tiene tanto que ver con la represión de las instituciones disciplinarias de los años setenta sino que conecta con las denominadas "enfermedades del vacío" -tratadas principalmente con psicofármacos- que se relacionan directamente con la extrema privatización de la experiencia y con la precarización de la vida9 . Lo que no ha cambiado es cómo las instituciones des-responsabilizan a los sujetos, otorgándoles el rol de meros espectadores de su

7 GASOL, Daniel; VALLDOSERA, Eulàlia, “Entrevista a Eulàlia Valldosera - Daniel Gasol” 2010. [En línea] http://salonkritik.net/09-10/2010/06/ [Consulta: 29 junio de 2010].

8 SARTRE, Jean-Paul, prefacio al libro Hacer de la enfermedad un arma (1972) [En línea] www.spkpfh. de/SARTRE preface FR.htm [Consulta: 20 noviembre de 2014].

9 En relación a tales ideas es preciso mencionar Indisposición general, ensayo sobre la fatiga (2015) de Martí Peran e Hijos de la noche (2014) de Santiago López Petit puesto que reflexionan sobre la dimensión política de la enfermedad y el malestar. 
angustia y desasosiego. Las actuales "psicopatologías de la nada" muestran como el capitalismo instrumentaliza la intimidad y una respuesta clara a este modo de hacer son los proyectos previamente mencionados de las artistas Eulàlia Valldosera y Jo Spence. En tales iniciativas las autoras trascienden los muros -explícitos e implícitos- de todo espacio terapéutico para mostrar y exponer tales procesos, siendo el objetivo final compartir y reapropiarse de la gestión del sufrimiento. Valldosera parte de las constelaciones familiares para aproximarse a ellas desde una perspectiva artística y, sobretodo, para enfatizar la dimensión sistémica del malestar y la capacidad de los individuos de abandonar el rol de sujetos pasivos.

Otro trabajo de Eulàlia Valldosera que se vincula con la estética del cuidado es Dependencia mutua (2010) (Fig. 4). Esta acción (vídeo-acción, 6') fue llevada a cabo en el Museo Arqueológico de Nápoles y, posteriormente, se presentó también en La Fábrica Galería en Madrid (2010). La artista pidió a la asistente familiar de la galerista que se convirtiera en su alter-ego y limpiara la escultura del emperador romano Claudio ubicada en el Museo Arqueológico de Nápoles. El trabajo también se com-

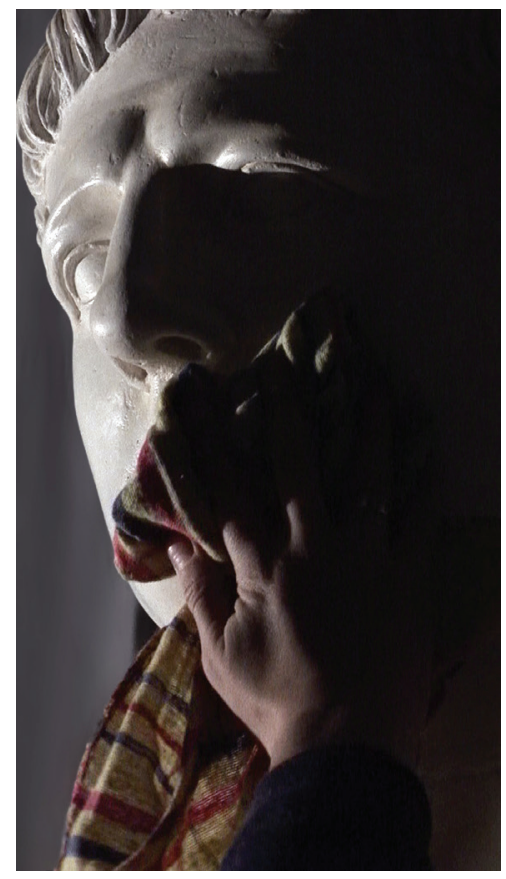

Fig. 4. Eulàlia Valldosera, Dependencia mutua (2010). Imagen cortesía de la artista. pone por una serie de fotografías y una entrevista a Liuba (Vídeo documental, 4'40"), en la que la asistente doméstica ucraniana describe sus tareas cotidianas a la vez que explica cómo llegó a Italia y su situación de inmigrante sin papeles. Aquí hay que destacar cómo Liuba, en el desarrollo de su relato vital, expone que trabaja sin contrato y que -según su opinión- a las mujeres les es más fácil encontrar empleo. En esta acción el acto de limpiar deviene un acto transgresivo, señalando y subvirtiendo los roles de poder establecidos. Cito a la artista:

"En el hacer inocente de Liuba, limpiando cada centímetro de la imponente estatua masculina, se despliega poco a poco una actitud creciente de poder. Aunque suene contradictorio, se trata de un poder que no implica superioridad sino que es ejercido desde el acatamiento y la sumisión. La consciencia que demuestra esa mujer respecto al lugar que ocupa en la sociedad es fundamental. Porque no es su aspecto naíf lo que conmueve sino su sabia humildad, su acercamiento sensual y caritativo, el despliegue de su arte de cuidar y reparar que resuelve con pragmatismo, sin alardes, sin 
soberbia; ella toca y acaricia la estatua sabiendo que toda figura de poder no es sino un muñeco, un fantasma encadenado a su papel en la sociedad" ${ }^{\circ}$.

Valldosera destaca la dependencia mutua entre la "subalterna" y la mujer "emancipada". Se necesitan mutuamente; Liuba precisa un medio de subsistencia y la galerista precisa a Liuba para ejercer su profesión. La artista vincula esta relación de dependencia y cuidado con el entramado del mundo artístico:

"En el corazón de este trabajo existe la intención de hablar de nuestra relación cultural para con los objetos destinados al Museo, y por ende del papel que cumplen conservadores, comisarios, directores y restauradores, así como todo aquél que desempeña una tarea, por importante o sencilla que sea, en el espacio artístico. Todos ellos deberían nombrarse cuidadores, pues participan de esa amplia gama de roles maternos que, sin diferencias de rango, son los encargados de mantener viva y actualizar la memoria de nuestro imaginario visual" ${ }^{11}$.

Valldosera hace referencia al "arte de cuidar" de Liuba y al papel de "cuidadores" de los diferentes agentes culturales. La autora revisa los roles predefinidos en diferentes estructuras, sea la familiar o la laboral ¿Quién cuida? ¿Cómo se concreta la praxis del cuidado? ¿Cuál es la posición que cada agente ocupa? La artista analiza estos papeles asignados y nos muestra la posibilidad de reubicarlos, de cambiarlos, de recolocarlos. La posibilidad de cambiar de perspectiva queda manifiesta en esta reflexión de Valldosera:

"Por otro lado este trabajo marca una diferencia respecto a los anteriores, siempre he estado performando en persona, y esta vez no lo hago, me sitúo en el lado contrario, actúo como jefa, y tengo a un subalterno haciendo lo que yo le digo, es decir, me sitúo del lado del poderoso, de la galerista, de la institución, porque esta situación también se da...Somos como unos seres que tenemos esa posibilidad, esa doble cara, esa libertad... es increíble. Para decir cuáles son tus pasos y tu trayectoria puedes adquirir un papel. En definitiva, estoy analizando el rol del artista en este sistema"12.

El situarse en "el lado del poderoso" para repensar las estructuras de poder es un tema que Santiago Sierra (1966, Madrid) aborda en sus propuestas artísticas, llevando al límite la opresión y explotación del sistema capitalista. Ejemplos de ello son la acción Línea de 160 tatuada sobre 4 personas (2000), realizada en El Gallo de Arte contemporáneo de Salamanca, en la que Sierra contrató a cuatro prostitutas para que se dejaran tatuar por el precio de una dosis de heroína, o bien cuando remuneró a personas de cabello oscuro para que se tiñeran de rubio en la Bienal de Venecia (2001). En muchos de sus proyectos reproduce los abusos perpetrados desde las estructuras

10 BLASCO, Jorge; VALLDOSERA, Eulàlia, "Entrevista a Eulàlia Valldosera por Jorge Blasco Dependencia mutua: Las fronteras han sido mi territorio de trabajo", Fe de errata\# revista de artes visuales/ / fronteras, migraciones y desplazamientos, Núm. 5, Colombia, 2011, p. 230.

11 Ibidem, p. 232.

12 GASOL, Daniel; VALLDOSERA, Eulàlia, op. cit. 
de poder y evidencia la precariedad laboral y las condiciones laborales indignas de los colectivos más vulnerables en el marco de las sociedades "desarrolladas"

Se trata de mostrar la realidad sin filtros y la creación se transforma en un medio -tanto para Eulàlia Valldosera como para Santiago Sierra- para enfocar cómo en el mundo del arte también se perpetran estas relaciones de poder. Aunque hay claras diferencias entre las propuestas de Sierra y Valldosera. Sierra asume la decisión de reproducir explícitamente la explotación laboral en sus proyectos artísticos mientras que la posición de Valldosera es ambigua. Ella decide que Liuba sea su alterego aunque también se convierte en su "jefa", reflexionando sobre la situación de las mujeres "emancipadas" que necesitan la figura de trabajadoras "subalternas". Valldosera ocupa distintos lugares y, de este modo, nos recuerda que los roles cambian, puesto que son dinámicos y están en construcción continua. Valldosera en estas obras da la voz a quienes han sido silenciados y silenciadas, vincula lo personal con lo colectivo al entender el arte como una actitud, como un compromiso.

\section{La ética del cuidado: Antikeres y la Trilogía de la privacidad de Nora Ancarola y Marga Ximénez}

El "arte de cuidar" y las vivencias de quienes asisten a las personas dependientes es el punto de partida de Antikeres, la tercera parte del proyecto artístico La trilogía de la privacidad de Nora Ancarola (Buenos Aires, 1955) y Marga Ximénez (Barcelona, 1950) $)^{14}$.

Trilogía de la Privacidad es un proyecto que se inició en 2004, llevado a cabo durante seis años, articulado a partir de tres ejes: la Sibila, Domus Aurea y Antikeres. Tal y como afirma la historiadora y curadora Sílvia Muñoz d'Imbert, en su texto Trilogía de la Privacidad como un todo, la propuesta toma como protagonista a las mujeres que han sido silenciadas quedando recluidas tradicionalmente en el espacio doméstico ${ }^{15}$. Seguidamente se bosquejarán brevemente los dos primeros capítulos del proyecto antes de tratar la parte que aquí nos ocupa: Antikeres. Sibila inaugura la Trilogía cuestionando la dictadura de los cánones de belleza socialmente impuestos. En esta primera parte las instalaciones y video-creaciones de Nora Ancarola y Marga

\footnotetext{
13 El artista comenta en una entrevista: "Con respecto a lo humillante, observo que tatuarse o masturbarse o estar aislado o rapado no son actos que podamos calificar como humillantes en sí mismos. Hay algo que los hace ver así: lo escalofriante es que estos actos se hagan por una remuneración. Ahí está la brutalidad. La remuneración es un sistema que permite la compra del cuerpo y el tiempo del trabajador. Busqué una forma efectiva de mostrarlo y creo haber acertado". Véase la entrevista completa en JARQUE, Fietta, "Entrevista a Santiago Sierra. Un artista produce objetos de lujo, así es poco convincente una idea de compromiso político", 2002. [En línea] www.elpais.com/diario/2002/07/13/babelia/1026515167_850215.html. [Consulta: 20 septiembre de 2013 ].

14 Nora Ancarola y Marga Ximénez son artistas y gestoras desde el año 2000 del Espacio artístico Mx Espai en Barcelona. Tal y como comenta Nora Ancarola: "Paralelamente a ir configurando el proyecto MXEspai 1010, Marga y yo fuimos creando una manera de trabajar en que lo personal y lo privado, lo profesional y lo creativo, lo relacional y lo social se fueron fusionando" Véase ANCAROLA, Nora, Trilogia de la privadesa, Nora Ancarola \& Marga Ximénez, (eds. Mxespai), Barcelona, Mxespai, 2011: 31.

15 Ibidem.
} 
Ximénez aluden a la realidad de las sibilas, estas figuras femeninas relacionadas con los oráculos, con los misterios. El personaje de la adivina es encarnado por la joven Sibila de Delfos y por la Sibila de Cumes, quien envejecía eternamente, recordando las distintas etapas de la existencia ${ }^{16}$. Aquí es preciso apuntar que en catalán "belleza" y "vejez" se pronuncian de un mismo modo (bellesa y vellesa) y las artistas remarcan -con este juego de palabras- la presión que la sociedad ejerce sobre las mujeres para conservar una "eterna" juventud. En Domus Aurea, en alusión a la casa que se hizo construir Nerón en Roma, las artistas trabajan el concepto de hogar como escenario principalmente femenino a partir de varias instalaciones y video-creaciones. Parten del mito del espacio doméstico como un marco de intimidad y protección, aunque también de desasosiego y opresión, puesto que tradicionalmente las mujeres han vivido recluidas en sus hogares.

En Antikeres (Fig. 5) aparece como eje vertebrador el cuidado, la dependencia y la atención a niños, ancianos y enfermos. En la mitología griega clásica las Keres eran los espíritus femeninos de la muerte y, para contrarrestarlas, las artistas invocan a las Antikeres para crear un espacio de cobijo para las cuidadoras y cuidadores. Antikeres nace como un proyecto coral, colaborativo, en el que las artistas invitan a diversas personas a que narren sus experiencias en relación al acto de cuidar. Nora Ancarola y Marga Ximénez durante un año estuvieron recibiendo 55 relatos con imágenes y, posteriormente, entrevistaron a los colaboradores y colaboradoras para presentarlos físicamente -mediante este registro audiovisual- en las distintas exposiciones realizadas de la Trilogía de la privacidad ${ }^{17}$. Tales vivencias generalmente permanecen en la esfera de lo privado y aquí el arte se transforma en un medio para visibilizarlas y compartirlas. Se trata de retornar a la sociedad lo que ésta invisibiliza; la tristeza, el dolor, la enfermedad, la vejez y la muerte. Aquí retomamos la premisa "lo personal es político" tal y como expone Nora Ancarola:

"Lo personal es político y el renombrar lo cotidiano. Desde hace ya varias décadas las mujeres hemos puesto a debate, desde nuestra incorporación masiva en la profesio-

\footnotetext{
16 En estrecha relación con esta voluntad de visibilizar la realidad de las mujeres que pertenecen a la llamada "tercera edad" la artista estadounidense Suzanne Lacy propuso el proyecto The Cristal Quilt (1987), realizada en el IDS Center Crystal Court de Minneapolis. En tal iniciativa Lacy invitó a 430 mujeres -mayores de 60 años-para que reflexionaran sobre el proceso de envejecimiento y su papel en la sociedad actual, siendo el encuentro emitido en la KTCA (la Televisión Pública estadounidense). Actualmente puede verse la obra a partir de un vídeo que captura este encuentro, documentales, fotografías, un edredón que recuerda la forma geométrica y los colores que articulaban el espacio del evento y una instalación en la que el espectador se sienta en una pequeña habitación con luz tenue para poder escuchar atentamente, en una atmósfera íntima, el testimonio de dichas mujeres. Esta acción colectiva parte del deseo de dar la palabra a las mujeres maduras, de diferentes orígenes y clases sociales, para recoger sus experiencias y difundir las ideas allí expuestas, debatidas y compartidas. Aquí el arte se transforma en una herramienta para abrir la consciencia, para dar que pensar y repensar. Asimismo, Suzanne Lacy es autora del libro Mapping the Terrain: New Genre Public Art (1995), en el que acuñó la expresión "nuevo arte público de género", muestra su interés para abordar estos temas tanto a nivel conceptual como desde una práctica artística activista.

17 Trilogía de la privacidad ha sido exhibida en el Instituto de Estudios Ilerdenses (Lérida, 2013), en el Centro de Arte Tinglado (Tarragona, 2013), en Carta D'Arte Mostra en Catània (Sicilia, 2012), Espai RocaUmbert (Granollers, 2011), Arts Santa Mònica (Barcelona, 2010), Centro de Arte Côte des Neiges (Montreal, 2008), TPK (Barcelona, 2007) y La Interior Bodega (Barcelona, 2004).
} 


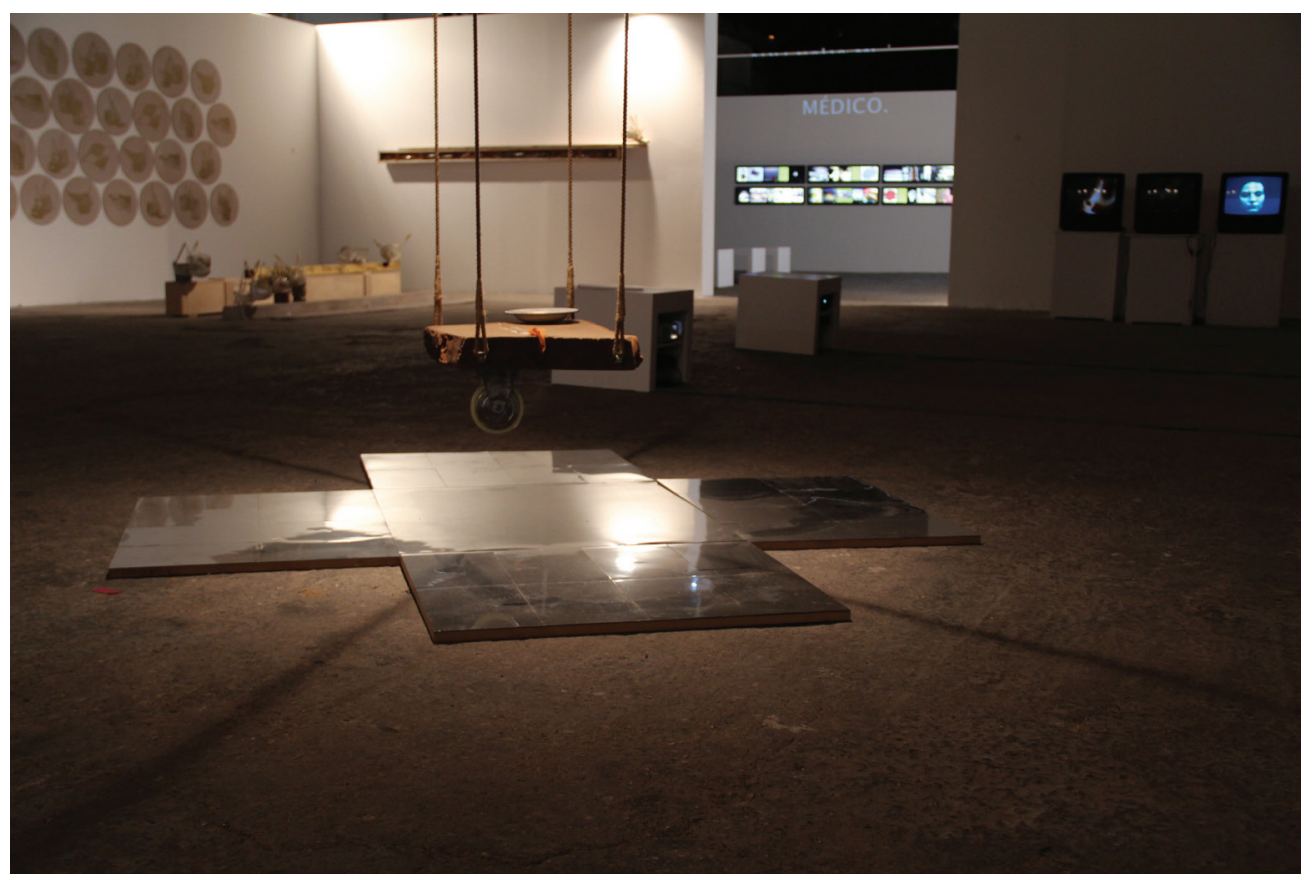

Fig. 5. Nora Ancarola y Marga Ximénez, Trilogía de la privacidad en el Centro de Arte el Tinglado, Tarragona (2013). Imagen cortesía de las artistas.

nalización dentro del mundo del arte, cuestiones como la representación del cuerpo o el concepto de privacidad, entendiéndolas como temas que competen a la sociedad en general. "Lo que es personal es político", la famosa frase de Carol Hanisch y el concepto desarrollado por Kate Millett ya en los años '60, fue la premisa desarrollada por innumerables artistas de la época, y que continúa hasta nuestros días lo demuestra”"18.

Silvia Muñoz d'Imbert, en su texto De la ética a la estética del cuidado: Antikeres, reflexiona sobre la atención a las personas dependientes en un contexto de crisis económica como el actual, recalcando que las mujeres asumen en la mayoría de los casos el cuidado de sus familiares dejando las actividades laborales fuera del ámbito del hogar. Muñoz d'Imbert cita a María Teresa López de la Vieja, en la obra El reto de la igualdad de género. Nuevas perspectivas en ética y filosofía politica, quien profundiza en esta situación ${ }^{19}$ :

"Los cuidados no remunerados de la salud tienen importantes consecuencias económicas, precisamente porque no son consideradas "trabajo" y, por lo tanto, no generan ni tienen reglamentación clara. Como sucede, por otra parte, con la actividad domésti-

18 ANCAROLA, Nora, op cit. p. 21.

19 MUÑOZ D’IMBERT, Silvia, Trilogia de la privadesa, Nora Ancarola \& Marga Ximénez, (eds. Mxespai), Barcelona, Mxespai, 2011, p. 77. 
ca, no está retribuida, no es contabilizada, y apenas es analizada en toda su complejidad. Tampoco es considera "trabajo productivo".

Muñoz d'Imbert remarca este maridaje entre el género femenino y el cuidado. Las Keres son los espíritus de la noche, de la muerte, y las Antikeres son los espíritus cuidadores y nos hacen pensar en la responsabilidad, en la solidaridad y en la empatía ${ }^{20}$. Con este proyecto se nos plantea la ética del cuidado, la realidad de los que acompañan y asisten a las personas dependientes. En estas iniciativas el arte se transforma en un medio para examinar las relaciones familiares y sociales. Nora Ancarola, en su videocreación Amor de madre (2011), también se adentra en su propio linaje superponiendo su rostro con el rostro de su madre 45 años después de su muerte, las imágenes se yuxtaponen quedando los retratos fundidos, entrelazados, evocando los rituales que la artista crea para procesar y compartir el duelo en la genealogía familiar. Nora Ancarola, al igual que Eulàlia Valldosera, de manera simbólica recupera y proyecta sus lazos familiares, el pasado con el presente, lo consciente y lo inconsciente.

Llegados a este enclave es preciso recordar cómo en la sociedad actual se desvincula el sufrimiento del marco político, económico y social. En tal contexto, la experiencia de la angustia es individual y -como ya se ha mencionado previamente- está monopolizada por la psicología y la psiquiatría que se han apropiado del dolor y se han transformado en las intérpretes "oficiales" del malestar, regulando así la experiencia del desasosiego. Los proyectos artísticos bosquejados parten de un trabajo coral, participativo, mostrando cómo los sujetos se responsabilizan de su padecimiento al tomar la iniciativa y reconectarse con la sociedad. El sufrimiento es devuelto a su carácter colectivo, deja de ser intervenido exclusivamente desde el prisma de la subjetividad que lo aísla del marco político y social.

Estas ideas quedan recogidas en la exposición Optimización Combinatoria. Ulla Blanca Lima en diálogo con Nora Ancarola, que tuvo lugar en La Xina A.R.T (del 12 de marzo al 16 de abril de 2016 en Barcelona). La muestra inicia su recorrido con la fotografía de una gandula verde (Fig. 6) que alude directamente a la relación entre ambas artistas y Ancarola explica que dicha gandula "simboliza las tácticas de apoyo a una alumna que, con una enfermedad crónica, pudo acabar con eficiencia sus estudios". Dicho de otro modo, la gandula representa una particular "optimización combinatoria" en la gestión de todos los recursos disponibles para resolver de la mejor manera factible ciertas problemáticas.

En esta muestra se exponen y comparten las estrategias que ambas concibieron y llevaron a cabo para facilitar que Ulla pudiera finalizar su formación artística en la Llotja y proseguir sus proyectos a pesar de su enfermedad, creando un espacio

20 En relación directa es preciso recordar la acción colectiva Carrying (1992) de Pepe Espaliú, realizada en las calles de Madrid siendo él mismo transportado por distintas parejas del Congreso de los Diputados a las puertas del Museo Reina Sofía (que era un antiguo hospital de tuberculosos) para visibilizar y concienciar sobre la problemática del VIH. El artista, quien padecía la enfermedad, comenta que en Carrying relaciona el verbo inglés To care (cuidar) y to carry (trasportar) aludiendo directamente a la necesidad de implicarse, actuar y colaborar. Véase PARDO, Tania, "Algunas propuestas de prácticas colaboractivas y relacionales en el contexto del arte contemporáneo español”. En Doctor Roncero, R. (Ed), Arte español contemporáneo 19922013, Madrid, La Fábrica, 2013, p. 162. 
de reposo en el aula. Forjaron un nuevo escenario desde la interacción y es preciso destacar las sinergias que se generaron entre la docente y la alumna en su voluntad de generar "otras maneras de hacer" y de relacionarse más allá de lo que pauta el marco académico. Puede verse que Ulla se desprende del rol de paciente y estudiante pasivo para adquirir un papel activo en la gestión de su enfermedad, siendo la creación un instrumento esencial para procesar su malestar, hacerlo visible y compartirlo con los

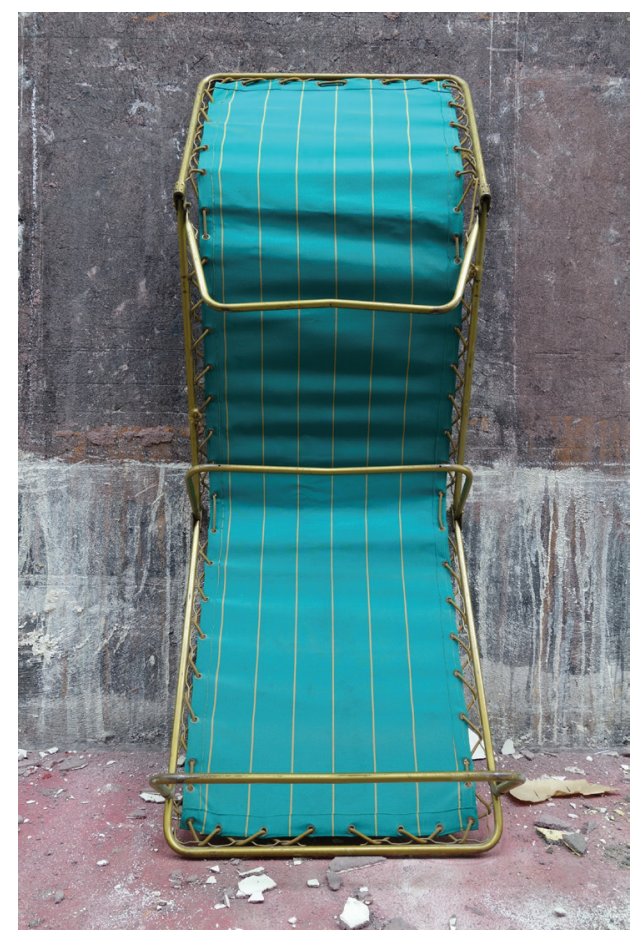

Fig. 6. Nora Ancarola y Ulla Lima, Optimización Combinatoria. Ulla Blanca Lima en diálogo con Nora Ancarola, Gandula, fotografía de Santi Erill, 2016. Imagen cortesía de las artistas.

otros compañeros del aula, con el resto de la comunidad educativa y con el público de los espacios artísticos en los que se exponen sus proyectos. También es pertinente mencionar que en la exhibición se presentó la instalación Estrategias de supervivencia I (2016) de Nora Ancarola, en la que aglutinaron unos relatos pictóricos que evocan una realidad rasgada- con el vídeo Triatlón (2009) que Ulla realizó para Antikeres. En dicho vídeo Ulla revela las imágenes de cuando Paula Carracelas la ayudaba a bañarse en un periodo de máxima dificultad. Lo personal deviene político.

En estas obras se plantean las relaciones personales y familiares, el cuidar y ayudar a quien lo necesita. Se trata de un compromiso personal y también colectivo en la decisión de compartirlo. Llegados a este punto no podemos dejar de mencionar, 
a pesar de la obviedad, que para poder cuidar de los otros es necesario cuidarse de uno o una misma. Como ya se ha visto en las propuestas previamente introducidas hay en un primer momento un trabajo personal, introspectivo, que luego revierte en la comunidad.

En relación directa con esta estética y ética del cuidado es pertinente citar al pensador Michael Foucault quien reflexiona sobre estos conceptos en una entrevista realizada por Raúl Fornet-Betancourt, Helmut Becker y Alfredo Gómez-Muller, el 20 de enero de 1984, titulada La ética del cuidado de sí como práctica de la libertad ${ }^{21}$. En la conversación el filósofo se refiere a los estados de dominación relacionados con las relaciones de poder -ya sean en el seno familiar, en un marco pedagógico o político$y$, en tal contexto, habla del cuidarse a sí mismo como un ejercicio de sí sobre sí en el intento de transformarse y autoformarse como sujeto. Foucault enlaza el cuidarse de uno mismo con el conocimiento pues "uno no puede cuidar de sí sin conocer"22, relacionándolo con la tradición socrática y platónica. El ethos griego, la manera de ser, impacta en la relación con uno mismo y con la comunidad, hay un cuidado de sí que se vincula con el cuidado de los otros que Foucault relaciona con el papel del filósofo ${ }^{23}$. Repensar el papel de la filosofía y del arte en la sociedad es esencial porque tal y como comenta el pensador "la cuestión del sujeto ético es algo que no tiene demasiado lugar en el pensamiento político contemporáneo" ${ }^{24}$. Foucault en su análisis del poder disciplinario profundiza en cómo los sujetos devienen cuerpos productivos, dóciles, sometidos. Las estructuras de poder se hacen cargo de la gestión de la vida de sus ciudadanos y, como respuesta a tal control, la filosofía y la creación ofrecen un marco en el que la vida puede entenderse como resistencia y aquí se entrelaza directamente con la construcción de discursos políticos alternativos.

Antikeres y la exposición Optimización Combinatoria. Ulla Blanca Lima en diálogo con Nora Ancarola ahondan en la eficacia simbólica de la creación, enfatizando la importancia de los trabajos colaborativos. El malestar no es exclusivo de las personas "diagnosticadas", deviene colectivo, político. La creación se transforma en una herramienta para devolver a la comunidad lo que supuestamente debe permanecer en el ámbito de lo íntimo y para enfocar la potencialidad de la vulnerabilidad.

\section{Conclusiones}

En el presente recorrido se constata que la creación artística y la filosofía asisten a las personas para transformarse en un ejercicio de conocimiento que repercute en el cuerpo social y colectivo. Antikeres, de Nora Ancarola y Marga Ximénez, y las obras previamente citadas de Eulàlia Valldosera comparten la misma voluntad de crear va-

21 FOUCAULT, Michael; FORNET-BETANCOURT, Raúl; BECKER, HELMUT; GÓMEZ-MULLER, Alfredo, "La ética del cuidado de sí como práctica de la libertad”, en Revista Concordia 6, 1984, pp. 96-116. [En línea] http://revistas.unc.edu.ar/index.php/NOMBRES/article/viewFile/2276/1217 [Consulta: 5 julio de $2014]$.

22 Idem, p. 6.

23 Idem, p. 8.

24 Idem, p. 16. 
sos comunicantes entre la experiencia personal y la colectiva. En estas correspondencias dan a conocer realidades que generalmente no traspasan la esfera de lo íntimo, pudiéndose constatar el compromiso y el activismo de dichas artistas puesto que entienden la creación como un instrumento de transformación social. Dicho de otro modo; el arte nos "afecta", nos mueve, nos conmueve, trabajando desde la empatía.

Las obras esbozadas ahondan en la estética del cuidado desde distintas perspectivas, comparten la voluntad de hablar en primera persona a la vez que facilitan que otras personas expongan sus experiencias en relación al cuidado, sea en un marco familiar o laboral. Aunque es preciso señalar que si bien Valldosera incluye en el proceso creativo a un terapeuta, en Constelaciones (2003) y en el taller "Constelaciones, espacios y relaciones" (2006), Nora Ancarola y Marga Ximénez prescinden de dicha figura y la creación se transforma en el único elemento de mediación con el malestar de las personas que participan en Antikeres (2004-2010).

Las entrevistas o diálogos son fundamentales en la metodología de trabajo de las artistas bosquejadas, siendo esencial la determinación de recoger otros relatos, otras narrativas, a la vez que responde a la voluntad de tomar la palabra, de que otras voces emerjan. Otra cuestión a considerar es la conciencia del acto de cuidar que tienen Nora Ancarola y Marga Ximénez, en su proyecto MX Espai (de 1998 hasta la actualidad) en el que crearon un marco para acoger proyectos e iniciativas artísticas que no tenían lugar en unos escenarios institucionales "oficiales", y Eulàlia Valldosera cuando manifiesta la relevancia de los roles maternos de los distintos agentes culturales que "son los encargados de mantener viva y actualizar la memoria de nuestro imaginario visual" "25. Esta estrecha conexión del cuidado con el género femenino está presente -desde distintos prismas- en el trabajo de dichas artistas. Todas las obras esbozadas han sido realizadas entrado el nuevo milenio, en el marco español, evidenciando que en la actualidad aún continúan siendo necesarias las reivindicaciones que Carol Hanisch planteaba en la década de los setenta. Nora Ancarola, Marga Ximénez y Eulàlia Valldosera recuerdan la premisa de que lo personal es político y se la apropian, la revisan, la actualizan.

En el arte de cuidar son fundamentales las relaciones que se establecen. La creación se nutre del contexto pudiéndolo conectar con el "arte relacional", siendo pertinente citar aquí al crítico y comisario francés Nicolas Bourriaud, quien en su libro Estética relacional (Esthétique relationnelle, 1998) analiza la creación relacionada con prácticas comunitarias, colectivas, concibiendo espacios de encuentro alternativos a los que ofrece el sistema capitalista ${ }^{26}$. Nicolas Bourriaud recoge la idea de rehabilitar la experimentación y la obra de arte como intersticio social:

"La posibilidad de un arte relacional (un arte que toma por horizonte teórico la esfera de las interacciones humanas y su contexto social, más que la afirmación de

25 BLASCO, Jorge; VALLDOSERA, Eulàlia, op. cit.

26 MANONELLES MONER, Laia, "Micro-utopías de lo cotidiano, espacios de encuentro en el arte relacional: una aproximación a ciertas acciones de Marina Abramović y Tino Sehgal”. En Bal, M. (Ed.), El arte (se) mueve: performatividad en el tiempo, el espacio y la forma. UNED, Madrid, SERIE VII · Historia DEL ARTE (NUEVA ÉPOCA) N. o 4, 2016, pp. 329-349. [En línea] http://revistas.uned.es/index.php/ETFVII/ article/view/16030/14338 
un espacio simbólico autónomo y privado) testimonia un giro radical de los objetivos estéticos, culturales y políticos puestos en juego por el arte moderno"27.

Con todo, este arte contextual, participativo, en el que la presencia del espectador es esencial porque forma parte del proceso creativo, no necesariamente tiene que tener un tamiz comprometido. Tania Pardo, en su artículo Algunas propuestas de prácticas colaborativas y relacionales en el contexto del arte contemporáneo español (2013), alerta de las posibles fisuras que este discurso genera, pues diversos autores como la crítica de arte Claire Bishop cuestionan que todo el "arte relacional" sea en esencia político, puesto que existe el riesgo de ser absorbido por la misma sociedad del espectáculo que se critica:

"Conectar a la gente, crear una experiencia interactiva y comunicativa -se pregunta Bishop-, pero ¿para qué? Creo que si uno se olvida del "para qué" queda en un mero "arte Nokia", que produce relaciones interpersonales por el solo hecho de hacerlo, sin llegar nunca a apelar a los aspectos políticos de esas relaciones" 28 .

Bourriaud replica a esta crítica que relaciona la estética relacional con "un arte sin efecto":

"Estas prácticas artísticas relacionales han recibido reiteradamente la misma crítica: en la medida en que se limitan al espacio de las galerías y de los centros de arte, estarían en contradicción con ese deseo de sociabilidad que funda su sentido. Se le reprocha así el estar negando los conflictos sociales, las diferencias, la imposibilidad de comunicarse en un espacio social alienado, en provecho de una modelización ilusoria y elitista, en tanto limitada al mundo del arte, de las formas de sociabilidad. Pero, ¿acaso se condenaba al pop-art porque reprodujera los códigos de la alienación visual? [...] La principal objeción que se ha planteado al arte relacional es la de representar una forma edulcorada de crítica social [...]. La exposición es un intersticio, que se define en relación con la alienación que reina en el resto del mundo. Reproduce o desplaza quizás las formas de esa alienación"29.

¿Podría decirse que las propuestas bosquejadas encajan dentro de esta "representación edulcorada de crítica social"? Dentro de las distintas variables de las prácticas colaborativas, políticas o apolíticas, hay que destacar que las propuestas aquí introducidas parten de una concepción artística que profundiza en la ética y la estética del cuidado. Es decir; bajo tales premisas el arte se convierte en un ejercicio de conocimiento y de transformación individual y social. Estos proyectos recogen las experiencias de quienes tienen una estrecha relación con las personas que cuidan, siendo

27 BOURRIAUD, Nicolas, "Estética relacional". En Blanco, P., Carrillo, J., Claramonte, J., Expósito, M. (Ed.), Modos de hacer, arte crítico, esfera pública y acción directa. Salamanca, Universidad de Salamanca, 2001, p. 430.

28 PARDO, Tania, "Algunas propuestas de prácticas colaboractivas y relacionales en el contexto del arte contemporáneo español”. En Doctor Roncero, R. (Ed), Arte español contemporáneo 1992-2013. Madrid, La Fábrica, 2013, p. 162.

29 BOURRIAUD, Nicolas, op. cit. p. 441-442. 
el cuidado un acto de amor, y también otras vivencias como la de Liuba, la asistente doméstica ucraniana de la galerista de Eulàlia Valldosera, para quien cuidar deviene un trabajo no regularizado.

Las iniciativas bosquejadas hablan desde la emoción, desde los sentimientos y los afectos. Nos conmueven apostando por la potencialidad de la vulnerabilidad, por la valentía de exponerse y de dejarse afectar. La reapropiación del malestar, retornándolo a la esfera pública, propicia que algo acontezca, que se forje un diálogo que pueda devenir un dispositivo para una transformación social a través de la acción colectiva. Tales propuestas rebasan los diques institucionales que privatizan lo público, los desalientos se convierten en un punto de inflexión pues se trascienden las pautas establecidas que "anestesian" el síntoma y lo aíslan de su esfera social. Amador FernándezSavater, en el artículo "Politizar el sufrimiento" manifiesta:

"El desafío que tenemos ante nosotros hoy es asumir el malestar como fuente de una nueva forma de politización que no pretenda cerrar la herida ("olvídate de tus problemas personales y ven a militar, la revolución es la salud"), sino mantenerla abierta como un vínculo vivo entre lo existencial y lo político del que se pueda extraer potencia de creación, de emancipación, de transformación. ¿Qué significaría politizar el sufrimiento $?^{30}$.

¿Qué significaría politizar el sufrimiento? En las propuestas presentadas el malestar se transforma en una materia prima del pensamiento crítico. Aquí es preciso retomar la determinación de hacer de la enfermedad un arma del Colectivo socialista de pacientes y el término "terapia política" (political therapy) de Carol Hanisch para subrayar la potencialidad catártica del colectivo en un contexto en el que el poder terapéutico se centra, principalmente, en mantener el engranaje de una sociedad enferma. Dentro de tales premisas, la creación puede entenderse como una actitud, como un compromiso. Los procesos son compartidos dentro de una ética relacional, siendo uno de los objetivos finales re-contextualizar, politizar y poetizar la existencia, la cotidianidad en la que vivimos.

\section{Bibliografía}

ANCAROLA, Nora; XIMÉNEZ, Marga, MUÑOZ D’IMBERT, Silvia, PLAZA, Elsa, DONAIRE, Lola; VALPIANA, Tatiana. (2011). Trilogia de la privadesa, Nora Ancarola \& Marga Ximénez. Barcelona: Mxespai.

BLASCO, Jorge; VALLDOSERA, Eulàlia. (2011). "Entrevista a Eulàlia Valldosera por Jorge Blasco Dependencia mutua: Las fronteras han sido mi territorio de trabajo". Fe de errata\# revista de artes visuales//fronteras, migraciones y desplazamientos, $\mathrm{N}^{\mathrm{o}}$ 5, Colombia, pp. 226-241.

30 FERNANDEZ-SAVATER, Amador, "Politizar el sufrimiento". Minerva, Revista del círculo de Bellas artes, $\mathrm{n}^{\circ}$ 7, 2008, p. 111. [En línea] www.revistaminerva.com/articulo.php?id=233 [Consulta: 18 febrero de 2015]. 
BOURRIAUD, Nicolas. (2001) "Estética relacional". En BLANCO, Paloma; CARRILLO, Jesús: CLARAMONTE, Jordi; EXPÓSITO, Marcelo. (Ed.), Modos de hacer, arte crítico, esfera pública y acción directa, Salamanca: Universidad de Salamanca.

LÓPEZ PETIT, Santiago (2014) Hijos de la noche. Barcelona: Bellaterra.

MANONELLES MONER, Laia. (2013). "Rumiar el malestar en las prácticas artísticas contemporáneas”. En ALBA, Tania; CIURANS, Enric; POLO, Magda. (Ed.), L'accionsime, en els límits de l'art contemporani. Barcelona: Publicacions de la Universitat de Barcelona.

MATA RUIZ, Iván; ORTIZ LOBO, Alberto (2007). "La colonización psiquiátrica de la vida". Archipiélago, cuadernos críticos de la cultura, vol. 76, pp. 45-46.

PARDO, Tania. (2013). "Algunas propuestas de prácticas colaboractivas y relacionales en el contexto del arte contemporáneo español". En DOCTOR RONCERO, Rafael (Ed), Arte español contemporáneo 1992-2013. Madrid: La Fábrica.

PERAN, Martí. (2015). Indisposición general, ensayo sobre la fatiga. Barcelona: Fabra i Coats, Centre d'art contemporani.

\section{Fuentes Electrónicas}

FERNÁNDEZ-SAVATER, Amador. (2008). "Politizar el sufrimiento". Minerva, Revista del círculo de Bellas artes, $\mathrm{n}^{\mathrm{0}}$ 7. [En línea] www.revistaminerva.com/ articulo.php?id=233 [Consulta: 18 febrero de 2015]

FOUCAULT, Michael; FORNET-BETANCOURT, Raúl; BECKER, HELMUT; GÓMEZ-MULLER Alfredo. (20 de enero de 1984). "La ética del cuidado de sí como práctica de la libertad”. En Revista Concordia 6, pp. 96-116. [En línea] http://revistas.unc.edu.ar/index.php/NOMBRES/article/viewFile/2276/1217 [Consulta: 5 julio de 2014].

GASOL, Daniel; VALLDOSERA, Eulàlia. (2010). "Entrevista a Eulàlia Valldosera - Daniel Gasol”. [En línea] http://salonkritik.net/09-10/2010/06/ [Consulta: 29 junio de 2010].

HANISH, Carol. (1969). "The Personal Is Political”. Notes from the Second Year: Women's Liberation. [En línea] www.carolhanisch.org/CHwritings/PIP.html [Consulta: 5 de abril el 2014].

JARQUE, Fietta. (2002). "Entrevista a Santiago Sierra. Un artista produce objetos de lujo, así es poco convincente una idea de compromiso político". [En línea] www.elpais.com/diario/2002/07/13/babelia/1026515167_850215.html [Consulta: 20 septiembre de 2013].

MANONELLES MONER, Laia. (2016) "Micro-utopías de lo cotidiano, espacios de encuentro en el arte relacional: una aproximación a ciertas acciones de Marina Abramović y Tino Sehgal". En Bal, M. (Ed.), El arte (se) mueve: performatividad en el tiempo, el espacio y la forma. UNED, Madrid, SERIE VII· Historia DEL ARTE (NUEVA ÉPOCA) N. ${ }^{\circ} 4$, 2016, pp. 329-349. [En línea] 
http://revistas.uned.es/index.php/ETFVII/article/view/16030/14338

NIETO, Marta. (2003) "La artista Eulalia Valldosera explora la comunicación en una muestra en BilbaoArte", El País, 28 de junio de 2003. [En línea] www.elpais. com/diario/2003/06/28/paisvasco/1056829219_850215.html [Consulta: 5 junio de 2013].

SARTRE, Jean-Paul. (1972). Prefacio al libro Hacer de la enfermedad un arma. [En línea] www.spkpfh.de/SARTRE_preface_FR.htm [Consulta: 20 noviembre de 2014].

VALLDOSERA, Eulàlia. (2013). "Valldosera invita a los artistas a conocerse a través de sus 'constelaciones' particulares". [En línea] www.eldiariomontanes.es/ prensa/20060809/cantabria/valldosera-invita-artistas-conocerse_20060809.html [Consulta: 5 junio de 2013]. 